\title{
Building relationships between scientists and business in ocean iron fertilization
}

\author{
Margaret Leinen* \\ Climos, 512 2nd Street, San Francisco, California 94107, USA
}

\begin{abstract}
The potential use of ocean iron fertilization (OIF) as a tool for either carbon reduction projects like those used to generate carbon credits or offsets, or for larger-scale mitigation to remove a significant percentage of $\mathrm{CO}_{2}$ from the atmosphere has interested the private sector. Scientists have highlighted the additional research that must be completed to understand the efficacy and impact of OIF at either scale. Carbon markets also place requirements on the nature of the credits generated if they are to be trusted and valued. The challenge for the future is to find effective ways for the science, business and carbon market communities to collaborate in ways that adhere to the high standards of scientific research. A code of conduct that recognizes the needs for scientific excellence and transparency, carbon market quality controls, and regulatory requirements like permitting can facilitate collaboration.
\end{abstract}

KEY WORDS: Ocean iron fertilization · Carbon mitigation · Carbon markets

\section{INTRODUCTION}

Scientists working in the Joint Global Ocean Flux Study (JGOFS) and the Surface Ocean Lower Atmosphere Study (SOLAS) have forged not only a new understanding of the way the biology, chemistry and physics of the ocean interact to control primary productivity in the ocean, but also new tools for studying biogeochemistry. The ocean iron fertilization (OIF) experiments of the last $15 \mathrm{yr}$ are unique examples of such a tool, the active manipulation of the ocean environment to study biogeochemical processes. These ambitious experiments, built on 10 successful bottle experiments that demonstrated the potential of iron to stimulate phytoplankton growth (e.g. Buma et al. 1991, Zettler et al. 1996), allowed the community to test hypotheses about controls on primary productivity in the open ocean. Several experiments also discussed their results in the context of hypotheses related to ocean productivity during glacial times (e.g. Coale et al. 1996, Boyd \& Law 2001), when dust fluxes to the open ocean were greater than during interglacial periods (Rea 1994, Winckler et al. 2008). While the experi- ments did not explicitly focus on the potential of OIF to sequester anthropogenic $\mathrm{CO}_{2}$, this possibility was clearly under discussion in symposia and workshops, as well as in the peer-reviewed literature (Spencer 1992). But the experiments were not well designed to answer fundamental research questions about carbon export and sequestration (e.g. de Baar et al. 2005, Boyd et al. 2007, Buesseler et al. 2008), much less $\mathrm{CO}_{2}$ mitigation.

Over the last $5 \mathrm{yr}$ the pace of scientific research demonstrating global change impacts due to anthropogenic greenhouse gases has been accelerating; e.g. Intergovernmental Panel on Climate Change (IPCC) summaries of warming (Solomon et al. 2007), syntheses of research on ocean acidification (Raven et al. 2005), and evidence of rapid changes in the extent of Arctic sea ice (see: nsidc.org/news/press/2007_seaiceminimum/ 20071001_pressrelease.html). The slow response of the global policy community to develop strategies for abating fossil fuel emissions (Canadell et al. 2007) and the emergence of the European Trading System (ETS) and Clean Development Mechanism (CDM) of the Kyoto Protocol (KP) (Harrison \& Radov 2002) led to increased 
interest in global change mitigation from the private sector and a surge of investment in clean technology and mitigation - for example an 18\% increase in venture investment in the first quarter (Q1) of 2008 over Q1 2007 (see: renewable.energystocks.com/news/051608.asp). The scale of the problem, together with these sources of funding and an emerging market for $\mathrm{CO}_{2}$ abatement (Bayon et al. 2007) have renewed interest in the potential of OIF as a mechanism for carbon sequestration.

The carbon markets - regulated and voluntarywant to assure that carbon credits are real and reflect true sequestration of carbon or abatement of emissions. The biogeoscience community brings specific concerns about carbon credits for OIF: sequestration must go beyond simple increases in gross primary production and must reflect new production, it must also account for any other greenhouse gases that are generated (e.g. $\mathrm{N}_{2} \mathrm{O}$ and $\mathrm{CH}_{4}$ ), the air/sea exchange of $\mathrm{CO}_{2}$ must be considered, and the length of time that the carbon is sequestered must be defined. Both groups are also concerned that the impact of OIF on the ocean be understood and that it be acceptable and responsible. The community has highlighted the fact that many questions related to sequestration and impact cannot be inferred from small-scale experiments $(10 \mathrm{~s}$ of $\mathrm{km}$ per side) because many processes do not scale linearly. This implies the need for a new set of OIF experiments that are in part justified by questions related to commercialization. A recent Science policy forum (Buesseler et al. 2008) emphasized these needs and called for new experiments at larger and longer time scales. These experiments must be of the highest scientific quality and they are, in part, motivated by research questions related to application, in addition to basic research questions.

The participation of private capital in funding experimentation is common in other fields, including some fields of oceanography (e.g. genomic prospecting, aquaculture), but is relatively new to ocean biogeochemistry. Although a recent community workshop expressed an openness to working on experiments motivated by commercial interest (Holmes 2008), it is clear that a strong set of guiding principles for such work are necessary to ensure that the results can be evaluated and that the researchers involved are not compromised. Some of the concerns can and are being addressed by the mechanisms of the regulated carbon market; others can be addressed by a strong scientific interaction between the biogeochemistry and marine ecology science communities and the community of businesses interested in the OIF process. I discuss some of the market regulating mechanisms that assist in this process as well as the roles that scientists and commercial interests can play in ensuring that questions on sequestration and impacts of OIF are addressed.

\section{CARBON MARKET CONTROLS ON QUALITY OF OFFSETS}

The regulated carbon markets established under the $\mathrm{KP}$ — the CDM and Joint Implementation (JI) — have a set of criteria for carbon credits or 'offsets' (Grubb et al. 1999):

(1) The markets require that credits are real, that they represent actual reductions in atmospheric $\mathrm{CO}_{2}$, and that they are measurable.

(2) The measurement of $\mathrm{CO}_{2}$ in the regulated market under the KP requires a methodology (see: cdm.unfccc. int/Reference/Procedures/index.html for a description of procedures), a rigorous, formula-based description of the measurements by which $\mathrm{CO}_{2}$ or other greenhouse gases are shown to be reduced. Each methodology undergoes an extensive review by a panel with expertise in many forms of $\mathrm{CO}_{2}$ reduction (see: cdm.unfccc. int/Panels/meth/index.html for the current Methodology Panel and its activities) and with the capability of engaging outside discipline experts (see: cdm.unfccc. int/Panels/meth/CallForExperts for the criteria used by the Methodology Panel to choose outside experts). OIF might well use models to describe aspects of sequestration. Methodologies can be based on model output, as in the case of forestation, where statistical models of growth, disease, age distribution, etc. are used to estimate total $\mathrm{CO}_{2}$ sequestered. Methodologies are typically revised multiple times to address concerns of the Methodology Panel and its experts. Some methodologies are rejected (the methodology portion of the CDM website provides information on methodologies that have been accepted, those being considered, and those that have been rejected: cdm.unfccc.int/methodologies/ index.html).

(3) Credits are also required to be 'additional,' that is, credit cannot be claimed for reductions that would have happened anyway because of regulation or planned technological upgrades. OIF would, of course, be 'additional' because carbon mitigation is the primary reason that it is contemplated, and the carbon market is the only rationale for commercial funding. This is not a minor point, as a common problem with carbon credit projects has been that they would have been done anyway. For example, some projects to sequester $\mathrm{CO}_{2}$ in oil wells would have been done to enhance oil recovery; some landfill gas projects were mandated by law.

(4) Credits must be permanent and markets rely on the IPCC definition of $100 \mathrm{yr}$ as permanent for sequestration projects (United Nations Framework Convention on Climate Change, UNFCCC 1997). The permanence definition is important because it sets the minimum age for carbon to be sequestered from any OIF project. The 100 yr choice was a policy decision, informed from scientific and policy deliberations on global warming potential (GWP), a method to normal- 
ize the heat trapping capabilities of the important greenhouse gases (e.g. $\mathrm{N}_{2} \mathrm{O}, \mathrm{CH}_{4}$, hydrofluorocarbons [HFCs]). GWP divides the cumulative lifetime radiative forcing per molecule of each gas against a reference time period of cumulative radiative forcing of a molecule of carbon dioxide (IPCC 1995). The IPCC (1995) calculated GWP for time periods of 20, 100, and $500 \mathrm{yr}$, and characterized the choice of 'time horizon' as a policy decision. In discussion of this, they noted:

'Policy-relevant climate-change phenomena exist at both ends of the climate-change time spectrum:

(1) If the policy emphasis is to help guard against the possible occurrence of potentially abrupt, non-linear climate responses in the relatively near future, then a choice of a 20 -year time horizon would yield an index that is relevant to making such decisions regarding appropriate greenhouse gas abatement strategies. In addition, if the speed of potential climate change is of greatest interest (rather than the eventual magnitude), then a focus on shorter time horizons can be used.

(2) Similarly, if the policy emphasis is to help guard against long-term, quasi-irreversible climate or climate-related changes (e.g. the very slow build up of and recovery from sea level changes that are controlled by slow processes such as warming of the ocean), then a choice of a 100-year or 500-year time horizon would yield an index that is relevant to making such decisions regarding appropriate greenhouse gas abatement strategies.

With this awareness, policies could choose to be a mix of emphases. GWPs with differing time horizons can aid in establishing such a mix. Indeed, that was the case in the Montreal Protocol deliberations, in which the long-lived, high-ODP [ozone depleting potential] gases were the initial focus and the shorter-lived, lower-ODP gases were subsequent focus.'

(IPCC 1995)

The KP adopted $100 \mathrm{yr}$ as the only time horizon for calculating GWP (UNFCCC 1997). All subsequent carbon credits have been normalized by this standard, including emissions reductions from sinks (e.g. forestry) as defined by the UNFCCC Reporting Guidelines:

'Annex I Parties should report aggregate emissions and removals of greenhouse gases, expressed in $\mathrm{CO}_{2}$ equivalent terms at summary inventory level, using GWP values provided by the IPCC in its Second Assessment Report.'

(UNFCCC 1996)

Subsequent discussion by the IPCC on the definition of permanence for forestry projects shows how the GWP approach can also be applied for calculating the benefit of any sequestration project of variable length as compared to a reference time period of $100 \mathrm{yr}$ :

'Absolute Global Warming Potentials (AGWPS) are calculated by integrating the total radiative forcing of an emissions pulse over a 100-year time horizon with no discounting. Relative GWPs are the ratio of this integral for a given GHG [greenhouse gas] to that of $\mathrm{CO}_{2}$, which serves as the reference gas. This approach could be applied to compare carbon sequestration projects of different lengths, although there is no requirement in the Protocol to use the same conventions in this context. The reference is 'permanent' (more than 100 years) removal (or emission) of 1 t $\mathrm{CO}_{2}$. ' (Watson et al. 2000)
Future regulation could choose a different permanence standard, or like the Montreal Protocol, change permanence standards with time. However, it is important to understand the reasons behind the choice of $100 \mathrm{yr}$ for permanence.

(5) Credits must also account for 'leakage' (e.g. carbon emissions generated in the process of creating reductions, increase in carbon emissions as a result of emission reductions elsewhere, etc.). OIF projects would certainly have to account for fuel used to transport iron to the site, but they would also have to account for any greenhouse gases generated as a result of fertilization (e.g. $\mathrm{N}_{2} \mathrm{O}, \mathrm{CH}_{4}$ ) and potentially for downstream nutrient depletion.

(6) Finally, a third party must verify credits to ensure that the $\mathrm{CO}_{2}$ reduction took place and that the methodology was followed. While no framework for quality can assure complete accuracy in measurement of carbon reductions, or complete compliance, the methodology and verification requirements of the KP have developed considerable trust in the applicable markets.

While OIF credits would not be eligible for KP markets at present because they are not generated within signatory countries, both voluntary markets and emerging regulated markets are sensitive to the need for 'quality' (referring to the degree to which credits meet the criteria discussed above) and are moving quickly toward adoption of standards. Starting in 1998, a partnership between the World Business Council for Sustainable Development (WBCSD) and the World Resources Institute (WRI) convened The Greenhouse Gas Protocol Initiative (GHG Protocol), a multi-stakeholder partnership of businesses, non-governmental organizations (NGOs), governments, and others. This effort resulted in Corporate Accounting and Reporting Standards (Corporate Standard, WBCSD \& WRI 2004) and the Greenhouse Gas Protocol for Project Accounting (GHG Protocol, WBCSD \& WRI 2006). The GHG Protocol provides guidance on best practices for development on projects. A group of other products of the process provide guidance for accounting in land use and forestry projects, grid electricity projects and other specialized sectors.

Both the KP and the GHG Protocol have benefited by substantial scholarly activity devoted to developing statistical methods for dealing with estimated carbon in credit situations in which $\mathrm{CO}_{2}$ is not captured permanently, but is stored temporarily (e.g. Godal et al. 2003) in soils (e.g. Smith et al. 1997) and forests (e.g. Noble \& Scholes 2001). Natural sinks for carbon such as soil, forest and deepwater ocean carbon (whether in the form of particulate or dissolved, organic or inorganic) also require modeling to determine the duration of sequestration. The scientific communities studying soils and forest carbon (cf. Noble \& Scholes 2001, Smith 
2004) have also had to address such challenges. Commercial entities in forestry have methodologies that have been accepted to measure permanence using models.

All voluntary markets currently do not require adherence to the GHG Protocol, but credits that have not adhered to the protocol requirements have been criticized publicly. The voluntary market has expanded very quickly from $1 \mathrm{Mt} \mathrm{CO}_{2}$ during 2005 to $25 \mathrm{Mt} \mathrm{CO}_{2}$ during 2006 (Capoor \& Ambrosi 2007) and nearly tripled in 2007 to $65 \mathrm{Mt} \mathrm{CO}_{2}$ (Capoor \& Ambrosi 2008). These figures represent only credits traded on exchanges like the Chicago Carbon Exchange (CCX) and not credits purchased in private transactions, such as the highly publicized requests for credits by major USA corporations Google and Yahoo or those transactions that would fulfill the agreements of power plants to offset $\mathrm{CO}_{2}$ emissions. Large 'bilateral' or off-exchange transactions are estimated to be many times the exchange-traded volume (Capoor \& Ambrosi 2008) and generally adhere to the GHG Protocol requirements or even more stringent requirements established by the buyers to ensure that they are not embarrassed by negative publicity. Thus, sale of any substantial carbon credit pool from OIF activities is likely to have the same requirements from buyers because its size would draw public scrutiny. A new effort to establish a Voluntary Carbon Standard (VCS) for projects selling carbon credits in a voluntary market was initiated by The Climate Group, the International Emissions Trading Association and the World Economic Forum in late 2005. After the release of 2 consultation documents, the VCS 2007 was released in November 2007 (www.v-C-s.org/documents.html).

The scientific community can play a powerful role in ensuring that any OIF carbon credits to offset $\mathrm{CO}_{2}$ emissions in emerging markets and future markets adhere to standards. Legislators developing emerging regulated markets in the USA (e.g. the Regional Greenhouse Gas Initiative, the market mandated by California's AB32, and markets proposed in current national legislation) are also keenly aware of the GHG Protocol requirements and have incorporated quality factors from the Protocol into pending legislation. Negotiations concerning the incorporation of OIF into any international regulated trading scheme, such as the ETS or any UNFCCC protocol that would follow the KP period (post-2012) would also consult with scientists familiar with OIF. Regulators will look to the scientific community for guidance on the means of quantifying $\mathrm{CO}_{2}$ sequestered by this technique. It is important that the ocean science policy research community and the ocean science research community familiarize themselves with the processes and standards for carbon credits to understand how best to interact with the markets on the issue of standards and quality if OIF does prove to be an acceptable mechanism for sequestering carbon.

\section{CONDUCTING OIF EXPERIMENTS WITH COMMERCIAL FUNDING}

Capital from private sources can fulfill 2 important requirements necessary to advance the investigation of OIF as a potential climate mitigation or carbon credit project technique. First, it can provide venture funding for costly initial moderate-scale demonstration experiments $(200 \times 200 \mathrm{~km})$ that are, at least in part, commercial development research difficult to justify for government research support. Second, it could provide a potentially sustainable source of funding for research into sequestration and impacts if conservative, verified results from initial demonstrations justify funding subsequent cruises.

The interest of the commercial community in funding moderate-scale experiments or demonstrations in order to address questions of sequestration and/or impact has led to an active discussion of the best way to ensure that the results of such experimentation can be evaluated by the scientific community. The elements of a code of conduct proposed by Climos (www.climos. com) were an early contribution to this discussion. The code addresses 3 aspects of commercial activity: regulatory concerns, carbon market concerns, and scientific/environmental concerns

The code proposes that any commercially funded activity should be in full compliance with applicable regulatory requirements (including the use of permits required under the London Convention of 1972), should include an environmental impact assessment, and should avoid sensitive areas such as marine protected areas, world heritage sites, etc. The purity of the iron compound being used for fertilization should also be known to ensure that it does not introduce concentrations of other elements or organic compounds that would endanger marine ecosystems.

The code proposes that commercial activities should also use the best practices of the carbon markets. These would include the development of a published, validated methodology that provides detailed information on the methods of determining the carbon sequestration and allows independent verification of results by third parties. Other quality aspects of carbon credits, such as calculation of baselines before and after fertilization (as well as in and out of the fertilized patch), calculation of all leakage, adherence to additionality and permanence criteria, should also be characteristics of the projects. Any credits derived from experiments or demonstrations should also be tracked and registered to prevent duplicate sale. 
The Climos code of conduct also proposes that scientific concerns about conduct of experiments should be addressed: measurements should be made using stateof-the-art techniques by individuals who are appropriately trained (i.e. experienced scientists and their graduate students and post-docs). All project specifications, including location, size, details of iron application, pre- and post-fertilization conditions and observed responses, including measured export, should be published immediately in an open format so that results are accessible to the public. Measurement techniques and raw data should also be provided if possible. Results should be available for publication in the open literature.

A recent 'Science' editorial (Buesseler et al. 2008) also contributes suggestions for the conduct of projects done with a view toward future commercialization, emphasizing the need for a broader range of measurements than were characteristic of most of the early fertilization experiments, the need for active collaboration between researchers and those with commercial interests, and consideration of partnerships between commercial interests as well as philanthropic and government sources of funding. These types of formal dialog (published codes of conduct, editorials/policy fora, workshops, documents) are important contributions toward building relationships of trust between the research and business communities interested in OIF.

\section{TIMELINE FOR BUILDING A RELATIONSHIP BETWEEN BUSINESS AND RESEARCH}

The evolving landscape of OIF for carbon sequestration has 3 phases: basic research experimentation, focused research and development, and potential deployment. The early experiments between 1993 and 2004 certainly fit into the basic research/experimentation phase. They were small in scale (most about $10 \times$ $10 \mathrm{~km}$ ), financed by research grants. These experiments definitively showed that OIF would result in phytoplankton blooms and provided some important insights into the role of iron in biogeochemical cycling. Because most experiments were limited in duration and small in scale, they often did not observe the termination of the blooms and export of carbon.

The science community has called for a new phase of moderate-scale experiments with explicit suggestions about the types of measurements necessary to determine whether OIF is an effective mechanism for removing atmospheric $\mathrm{CO}_{2}$ (Boyd et al. 2007, Buesseler et al 2008). Such experiments could be funded in partnership with commercial interests with the objective of understanding controls on sequestration, assessment of environmental impact and modeling of permanence, and atmospheric drawdown (Holmes 2008). Because the goals of credible carbon markets are congruent with those of researchers (proof of sequestration by accepted techniques, knowledge of the permanence of the sequestration, accounting for leakage and environmental impact, etc.), if sequestration is demonstrated, carbon offsets from these experiments can be validated, verified and marketed without impacting the quality of the science that is done or creating intellectual conflicts for researchers. This is certainly the case in forest carbon sequestration. This focused research or development phase is critical to understanding the potential of OIF to sequester carbon.

Only after such focused research - and only with knowledge and acceptance of environmental impacts — should more routine (e.g. repetitive yearly projects in a certain area under a single permit) and/or largerscale deployment be undertaken. By larger-scale deployment I refer to fertilization of large patches several degrees of latidude/longitude per side or fertilization of significant percentages of specific ocean areas such as have been considered in some models (e.g. Gnanadesikan et al. 2003, Jin et al. 2008). This larger scale would almost certainly require regulated market acceptance for finance. The scientific community would also need to participate actively in the definition of limits to deployment to ensure that environmental impacts would be acceptable.

\section{SUMMARY}

While private sector funding for OIF development presents challenges, the desire of both oceanographic researchers and carbon markets for high standards of excellence are complementary. These common cultures can be leveraged to ensure that OIF development research is carried out in a responsible and transparent way even if funded by the private sector.

Acknowledgements. The manuscript benefited from the comments of 2 anonymous reviewers, one of whom substantially improved the manuscript by pointing out which concepts from the carbon markets were unfamiliar to the science community and needed further discussion. I would also like to thank K. Whilden and D. Whaley of Climos, both of whom reviewed the manuscript and provided helpful suggestions for its improvement.

\section{LITERATURE CITED}

Bayon R, Hawn A, Hamilton K (2007) Voluntary carbon markets: An international business guide to what they are and how they work. Earthscan, London

Boyd PW, Law CS (2001) The Southern Ocean Iron RElease Experiment (SOIREE) - introduction and summary. DeepSea Res II 48:2425-2438 
Boyd PW, Jickells T, Law CS, Blain S and others (2007) Mesoscale iron enrichment experiments 1993-2005: synthesis and future directions. Science 315:612-617

Buesseler KO, Doney SC, Karl DM, Boyd PW and others (2008) Ocean iron fertilization-moving forward in a sea of uncertainty. Science 319:162

Buma AGJ, Baar HJW, Nolting RF, Bennekom AJ (1991) Metal enrichment experiments in the Weddell-Scotia Seas: effects of iron and manganese on various plankton communities. Limnol Oceanogr 36:1865-1878

Canadell JG, Le Quere C, Raupach MR, Field CB and others (2007) Contributions to accelerating atmospheric $\mathrm{CO}_{2}$ growth from economic activity, carbon intensity, and efficiency of natural sinks. Proc Natl Acad Sci USA 104: 18866-18870

Capoor K, Ambrosi P (2007) State and trends of the carbon market 2007. International Emissions Trading Association, World Bank Institute, Washington, DC

Capoor K, Ambrosi P (2008) The World Bank state and trends of the carbon market. International Emissions Trading Association, World Bank Institute, Washington, DC

Coale KH, Johnson KS, Fitzwater SE, Gordon RM and others (1996) A massive phytoplankton bloom induced by an ecosystem-scale iron fertilization experiment in the equatorial Pacific Ocean. Nature 383:495-501

de Baar HJW, Boyd PW, Coale KH, Landry MR and others (2005) Synthesis of iron fertilization experiments: from the Iron Age in the Age of Enlightenment. J Geophys Res 110: C09S16

Gnanadesikan A, Sarmiento JL, Slater RD (2003) Effects of patchy ocean fertilization on atmospheric carbon dioxide and biological production. Global Biogeochem Cycles 17: 1050

Godal O, Ermoliev Y, Klaassen G, Obersteiner M (2003) Carbon trading with imperfectly observable emissions. Environ Resour Econ 25:151-169

Grubb M, Vrolijk C, Brack D (1999) The Kyoto Protocol: a guide and assessment. Royal Institute of International Affairs/Earthscan, London

Harrison D, Radov DB (2002) Evaluation of alternative initial allocation mechanisms in a European Union greenhouse gas emissions allowance trading scheme. Prepared for DG Environment, European Commission. NERA, Cambridge, MA

Holmes P (2008) Fertilizing the ocean with iron. Oceanus, Woods Hole, MA

IPCC (Intergovernmental Panel on Climate Change) (1995) Climate change 1994: radiative forcing of climate change and an evaluation of the IPCC IS92 Emission Scenarios. Cambridge University Press, Cambridge

Jin X, Gruber N, Frenzel H, Doney SC, McWilliams JC (2008) The impact on atmospheric $\mathrm{CO}_{2}$ of iron fertilization induced changes in the ocean's biological pump. Biogeosciences 5:385-406

Submitted: January 9, 2008; Accepted: May 20, 2008
Noble I, Scholes RJ (2001) Sinks and the Kyoto Protocol. Climate Policy 1:5-25

Raven J, Caldeira K, Elderfield H, Hoegh-Guldberg $\mathrm{O}$ and others (2005) Ocean acidification due to increasing atmospheric carbon dioxide. Roy Soc London Policy Document 12-05:60

Rea DK (1994) The paleoclimatic record provided by eolian deposition in the deep sea: the geologic history of wind. Rev Geophys 32:159-195

Smith P (2004) Monitoring and verification of soil carbon changes under Article 3.4 of the Kyoto Protocol. Soil Use Manag 20:264-270

Smith P, Powlson D, Glendining M, Smith JO (1997) Potential for carbon sequestration in European soils: preliminary estimates for five scenarios using results from long-term experiments. Glob Change Biol 3:67-79

Solomon S, Qin D, Manning M, Chen Z and others (2007). Climate change 2007, The physical science basis. Contribution of Working Group I to the Fourth Assessment Report of the Intergovernmental Panel on Climate Change, Cambridge University Press, Cambridge

Spencer DF (1992) An overview of energy technology options for carbon dioxide mitigation. Climate change and energy policy: Proc Int Conf on Global Climate Change, Its Mitigation Through Improved Production and Use of Energy, Los Alamos National Laboratory, October 21-24, 1991, Los Alamos 16:259-273

UNFCCC (United Nations Framework Convention on Climate Change) (1996) Updated UNFCCC reporting guidelines on annual inventories following incorporation of the provisions of decision 14/CP.11. In: UNFCCC (ed) FCCC/ SBSTA/2006/9

UNFCCC (1997) Report of the conference of the parties on its third session, held at Kyoto from 1 to 11 December 1997. In: UNFCCC (ed)

Watson RT, Noble IR, Bolin B, Ravindranath NH, Verardo DJ, Dokken DJ (2000) Land use, land-use change and forestry. A special report of the IPCC. Intergovernmental Panel on Climate Change, Cambridge University Press, Cambridge

WBCSD \& WRI (World Business Council for Sustainable Development and World Resources Institute) (2004) A corporate accounting and reporting standard. Available at: www.ghgprotocol.org/standards/corporate-standard

WBCSD \& WRI (World Business Council for Sustainable Development and World Resources Institute) (2006) GHG Protocol for Project Accounting. Available at: www. ghgprotocol.org/standards/project-protocol

Winckler G, Anderson RF, Fleisher MQ, McGee D, Mahowald $N$ (2008) Covariant glacial-interglacial dust fluxes in the equatorial Pacific and Antarctica. Science 320:93-96

Zettler ER, Olson RJ, Binder BJ, Chisholm SW, Fitzwater SE, Michael Gordon R (1996) Iron-enrichment bottle experiments in the equatorial Pacific: responses of individual phytoplankton cells. Deep-Sea Res II 43:1017-1029

Proofs received from author(s): July 6, 2008 